\title{
The Effect of Grain Refining of Primary Aluminum on the Fluidity of Al-Si Casting Alloys
}

\author{
Adefuye Olusegun \\ Department of Mechanical Engineering, Lagos State University \\ Epe, Lagos State, Nigeria \\ Tel: +2347082380475 E-mail: Olusegun.adefuye@lasu.edu.ng \\ Orisaleye Joseph \\ Department of Mechanical Engineering, University of Lagos \\ Akoka, Nigeria. \\ Tel: +2348060650837 E-mail: jorisaleye@unilag.edu.ng \\ Fadipe Opeyemi \\ Department of Mechanical Engineering, Lagos State University \\ Epe, Lagos State, Nigeria \\ Tel: +2348078304694 E-mail: opeyemi.fadipe@lasu.edu.ng \\ Adedeji kasali (Corresponding author) \\ Department of Mechanical Engineering, Lagos State University \\ Epe, Lagos State, Nigeria \\ Tel: +2348023430868 E-mail: kasali.adedeji@lasu.edu.ng
}

\begin{abstract}
Aluminium alloys, and particularly aluminium silicon alloys, have found extensive use in engineering applications. Improving the mechanical properties of the cast alloys is important. One of the means of achieving this is by grain refinement using grain refiners. The grain refiners affect the fluidity, and consequently solidification, of the alloys. In this study, the fluidity of nineteen Al-Si alloys made with silicon of $99.999 \%$ purity and aluminum of $99.999 \%$ purity were investigated using a straight channels mold. The casting modulus of the channels varied between 0.2 $\mathrm{mm}$ and $2.9 \mathrm{~mm}$. Using the same quality of materials, Ti-B-Al was added to alloys with silicon content between $0 \%$ and $16 \%$. In the $0.91 \mathrm{~mm}$ modulus channel a decrease varying from $50 \%$ to $2 \%$ was observed in the solid solution alloys while in the hypo-eutectic alloys fluidity decreased by $16 \%$ to $45 \%$. However, in the hyper-eutectic alloys, fluidity increased by $8 \%$ to $18 \%$.
\end{abstract}

Keywords: Fluidity, casting, grain-refinement, solidification

DOI: $10.7176 / \mathrm{CMR} / 13-1-05$

Publication date: April 30th 2021

\section{Introduction}

The aluminum-silicon alloys with silicon content between $0.5 \%$ and $20 \%$ are an important group of engineering casting alloys. The alloys have desirable physical, chemical, and mechanical properties, especially their high strength to mass ratio. Their importance lies much in their mechanical strength which is developed by grainrefinement of their primary phase or by the modification of their eutectic structure (Adefuye, 2014). Aluminium alloys based on the Al-Si system are the most versatile of the common foundry metals due to diverse aspects which include relatively low melting temperature, negligible solubility for all gases except hydrogen, good surface finishing and good fluidity, although there are some exceptions (Bolzoni et al., 2013).

These alloys have found wide applications in automobile industry which exploits their weight saving capabilities to achieve more reduction of fuel consumption (Kumar et al., 2015).Casting fluidity (or simply fluidity) measures, in some manner, the ability of liquid alloy to fill a mold. From the review by Di Sabatino and Arnberg (2004), fluidity has been defined as the ability of molten metal to flow before stopped by solidification. Fluidity is 
important to casting as it should specify whether or not a material is suitable for producing a casting based on the shape and dimensions of the casting only (Niu et al., 2019). Fluidity not only influences material castability, but also the casting properties. According to Ravi et al. (2008), fluidity is a primary issue that must be addressed in producing thin wall castings.

Di Sabatino and Arnberg (2004) and Ravi et al. (2008) found that fluidity is influenced by composition and trace addition, melt superheat, grain refinement, melt quality and cleanliness, viscosity, surface tension and oxide film. The factors that affect fluidity may be grouped into three. These include mould properties, alloy properties and process variables. The greater the chilling power of the mold the shorter the fluidity length. Thus mould materials, the grain size and mold dressings affect the fluidity of metals and alloys.

The mechanical properties of cast metals are significantly influenced by the grain size and morphology. To this end, desired mechanical properties can be achieved through altering the grain microstructure morphology (Sunitha and Gurusami, 2020). The methods adopted to achieve grain refinement include controlling the cooling rate of melted aluminium, addition of grain refiners in the form of master alloys to molten aluminium alloy and mechanical agitation during solidification through induced vibration, electromagnetic or ultrasonic stirring (Sunitha and Gurusami, 2020). Bolzoni and Babu (2019) and Sunitha and Grursami (2020) noted that chemical inoculation of aluminium alloys is a standard and general industrial procedure for grain refinement. This is carried out by adding Al-Ti-B or Al-Ti-C master alloys, also referred to as grain refiners, to the molten metals which lead to finer grains. The benefit of inoculation is that the fluidity of the alloy increases and the number of defects and micro- and macro-porosity decreases (Quested, 2004; Sunitha and Gurusami, 2020).

Easton et al. (2016) noted that earlier studies had shown that the addition of other elements to metal prior to solidification generally leads to a transition from columnar to equiaxed grain morphologies, although the effects of second phases and eutectics were also observed. However, Spittle (2006) highlighted the factors affecting grain refinement. These include the type of grain refiner, level of addition, holding time and fade, residual Ti levels, type of casting alloy and cooling rate.

Birol (2012) and Birol (2013) investigated the capacity of some Al-Ti-B grain refiners to refine grain structures of some aluminium foundry alloys. A marked improvement was achieved in the grain refining efficiency when AlTi-B ternary alloys were employed in grain refinement. It was noted that aluminium castings can achieve grain sizes below $200 \mu \mathrm{m}$ upon addition of grain refiners.

This paper aims to investigate the difference between the fluidity of pure metal and alloys in the Al-Si system and the fluidity of the same metal or alloys when it has been grain refined by the addition of a suitable grain refiner using very pure materials. It also aims to represent the different types of Al-Si casting alloys on the phase diagram adequately.

\section{Theory}

Fluidity is an index that is meant to indicate how well a liquid metal (or alloy) under a given process condition will fill a mold cavity on casting (Spittle, 2006). It is generally defined as the length through which a liquid metal or alloy will flow in a standard fluidity test channel before being arrested by solidification. It is different from, and longer than continuous fluidity, which is the length a liquid metal will fill before solidification starts (Campbell, 1995; Campbell, 2003).

Perhaps the most important factor that affects the fluidity of a material is its mode of solidification. Solidification of very pure metals progresses by uniform advancement of plane solidification front from the walls of the test channel to the liquid. Flow is arrested when the plane solidification fronts from all the sides of the wall meet (Piwonka, 1998). For an alloy with low solute content, the solidification front is rough. Columnar dendrites from the walls of the channels grow into the liquid. Dendrites from opposite sides of the wall grow into each other to form a solid mesh. The flow of the liquid metal is arrested when the permeability of the solid mesh is sufficiently low to prevent flow of the liquid alloy through it. In alloys with a high solute content and in which nucleation is not difficult, solidification starts by nucleation of equiaxed dendrites (Di Sabatino, 2005). The number of the dendrites increases with progress in solidification. When the volume of the dendrites is sufficiently high the flow is arrested.

The pouring temperature also affects the fluidity, the higher the superheat the longer the fluidity. Fluidity has generally been found to increase with decrease in solidification temperature range (Ravi et al., 2008). However, this has not been true of Al-Si alloys as the eutectic does not have a higher fluidity than the other alloys in the Al- 
Si system. Turbulence in the flow of the liquid metal or alloy reduces its fluidity. Clean melting and pouring practices improves fluidity. The metal head affects the metals and alloys differently. Increase in metal head increase the fluidity in pure metals and solute rich alloys. The strength of Al-Si alloys is improved by additives that refine the primary phase.

\subsection{Experimental methods}

Two sets of experiments were performed. The first set of experiments was to determine the fluidity of pure Al-Si alloys whilst the second set was to determine the fluidity of Al-Si alloys to which Ti-B-Al (a primary aluminum grain refiner) has been added.

The percentage content of aluminum in the ingots used to prepare the alloys was at least $99.999 \%$ while the percentage silicon content in the silicon used to prepare the alloys was $99.9999 \%$. The Ti-B-Al used for grain refinement of the primary aluminum consists of $5 \%$ by weight of titanium, $1 \%$ of boron and $94 \%$ of aluminum.

For the determination of the base-line fluidity values, the alloys were melted in an electromagnetic induction furnace (E.M.A.) and poured at $750^{\circ} \mathrm{C}$ through a cup filter and an offset weir basin into the multi-channel fluidity test mold.

Figure 1 illustrates the pattern used to prepare the fluidity test mold. Each test channel was $504 \mathrm{~mm}$ long and 20 $\mathrm{mm}$ wide. The depths of the channels were $1 \mathrm{~mm}, 2 \mathrm{~mm}, 3 \mathrm{~mm}$, and $4 \mathrm{~mm}$.

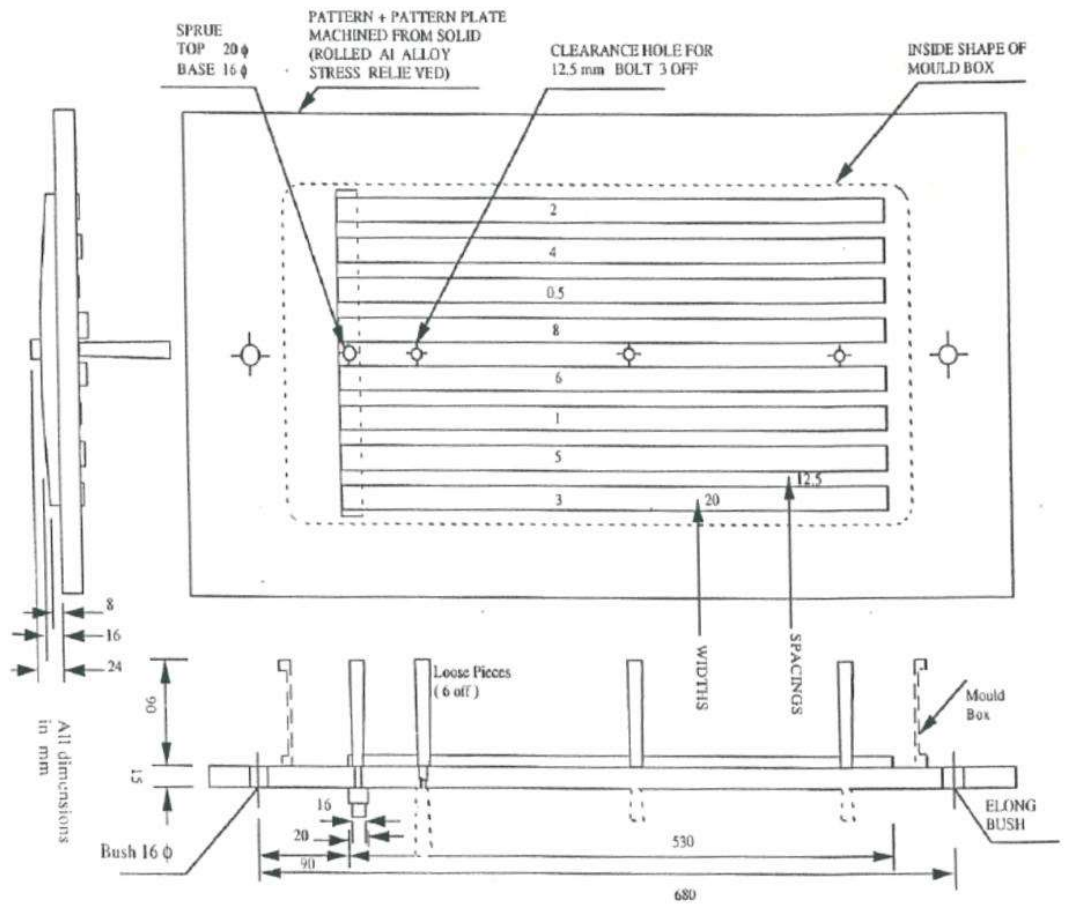

Figure 1: The pattern for the fluidity test mold

The mold was prepared with silica sand of grain size 60\# and 'pepset'was used as the binder. A preheated graphite plunger was used to plug the sprue entrance and was not removed until the basin was full. The alloys that were investigated had silicon content of $0,0.5,1.0,1.5,2.0,4.0,6.0,8.0,10.0,11.0,12.0,13.0,14.0,15.0,16.0,17.0$, $18.0,19.0$, and $20.0 \%$ by weight. In alloys to which the primary aluminium grain refiner was added, Ti-B-Al was added at $725^{\circ} \mathrm{C}$ and poured at $750^{\circ} \mathrm{C}$.

For the purpose of this work fluidity is defined as the volume of the test strip divided by the cross-sectional area. The casting modulus is defined as the cross-sectional area of the test-channel divided by its perimeter Macroscopic and microscopic investigation including the preparation of macroscopic montage of selected strips was carried out. Particle analysis of the primary phase and x-ray investigation of the test strips were also undertaken. 


\section{Results and discussion}

The silicon contents of the Al-Si alloys used were varied. The composition of the alloys, to which Ti-B-Al was added, based on the variation and is shown by Table 1 .

Table 1: Detailed composition of alloys to which Ti-B-Al was added

\begin{tabular}{lcccc}
\hline ALLOY & \multicolumn{4}{c}{ COMPOSITION (by \%weight) } \\
\cline { 2 - 5 } & $\mathrm{Al}$ & $\mathrm{Si}$ & $\mathrm{Ti}$ & $\mathrm{B}$ \\
\hline $\mathrm{Al}-0 \% \mathrm{Si}$ & 99.860 & 0.000 & 0.117 & 0.023 \\
$\mathrm{Al}-0.5 \% \mathrm{Si}$ & 99.390 & 0.490 & 0.100 & 0.020 \\
$\mathrm{Al}-1 \% \mathrm{Si}$ & 98.900 & 0.980 & 0.100 & 0.020 \\
$\mathrm{Al}-1.5 \% \mathrm{Si}$ & 98.410 & 1.470 & 0.100 & 0.020 \\
$\mathrm{Al}-2 \% \mathrm{Si}$ & 97.900 & 1.980 & 0.100 & 0.020 \\
$\mathrm{Al}-4 \% \mathrm{Si}$ & 95.900 & 4.000 & 0.080 & 0.020 \\
$\mathrm{Al}-6 \% \mathrm{Si}$ & 93.900 & 5.930 & 0.060 & 0.110 \\
$\mathrm{Al}-8 \% \mathrm{Si}$ & 91.960 & 8.000 & 0.033 & 0.007 \\
$\mathrm{Al}-10 \% \mathrm{Si}$ & 88.030 & 9.920 & 0.042 & 0.008 \\
$\mathrm{Al}-12 \% \mathrm{Si}$ & 88.030 & 11.940 & 0.025 & 0.005 \\
$\mathrm{Al}-13 \% \mathrm{Si}$ & 86.980 & 12.990 & 0.025 & 0.005 \\
$\mathrm{Al}-16 \% \mathrm{Si}$ & 84.170 & 15.800 & 0.025 & 0.005 \\
\hline
\end{tabular}

The fluidity of untreated Al-Si alloys is illustrated by Figure 2. The pure aluminum is the most fluid material. It filled all the fluidity test channels except the $0.48 \mathrm{~mm}$ modulus channel. Its fluidity in the filled channels could not be determined by the test. The high fluidity of the metal may be attributed to its mode of solidification. It has been shown from metallographic studies and print of x-ray diffraction mottles that the flow of pure aluminum in the fluidity channels was arrested by growth of planar solidification front. The flow of the solid solution alloys and the hypo-eutectic alloys was arrested by the presence of equiaxed aluminum dendrites near the tip of the test strips. The flows of the eutectic and the hyper-eutectic alloys were arrested by the presence of critical amount of eutectic cells near the tip of the test strip (Adefuye, 2006).

The fluidity test channel with a modulus of $1.67 \mathrm{~mm}$ was completely filled by alloys with silicon content of $12 \%$ and above. The higher fluidity of the near eutectic and the hyper-eutectic alloys is as a result of the latent heat of fusion the silicon liberated during the solidification of these alloys.

The fluidity of the Al-Si alloys to which primary aluminum phase refiner Ti-B-Al was added is illustrated by Figure 3.

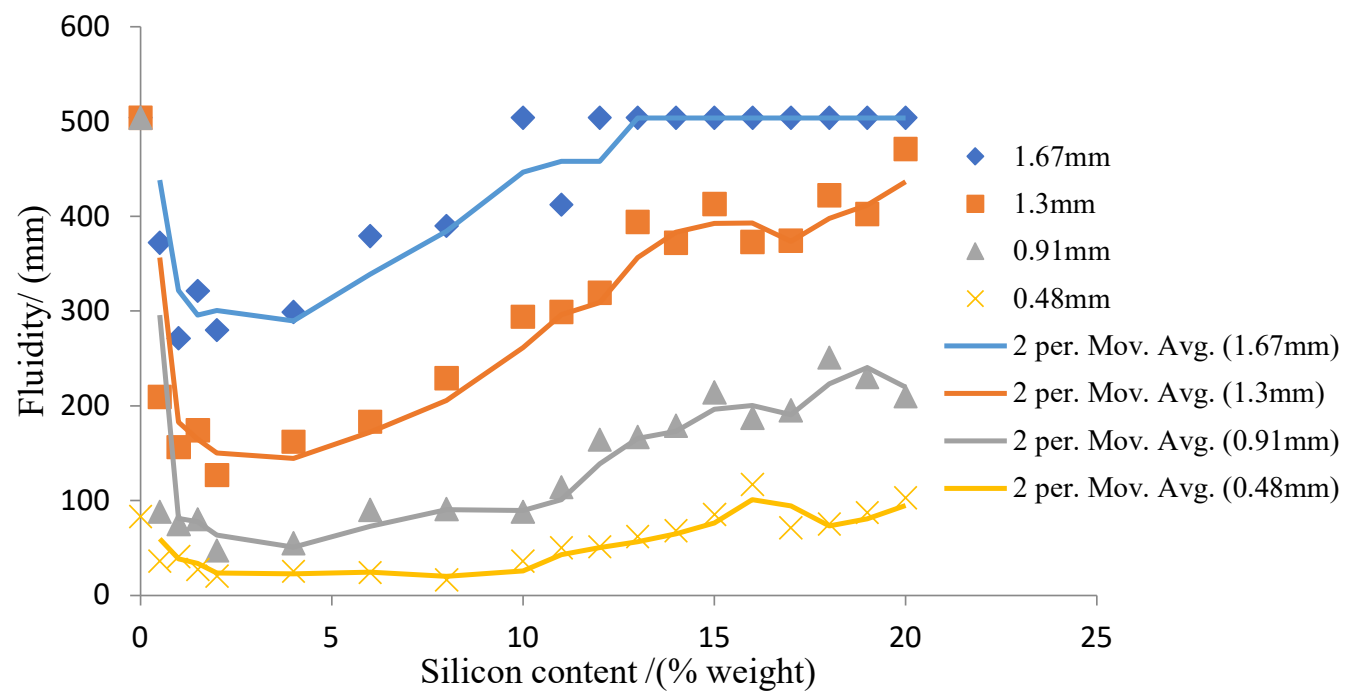

Figure 2: Fluidity as a function of silicon content and test channel modulus 


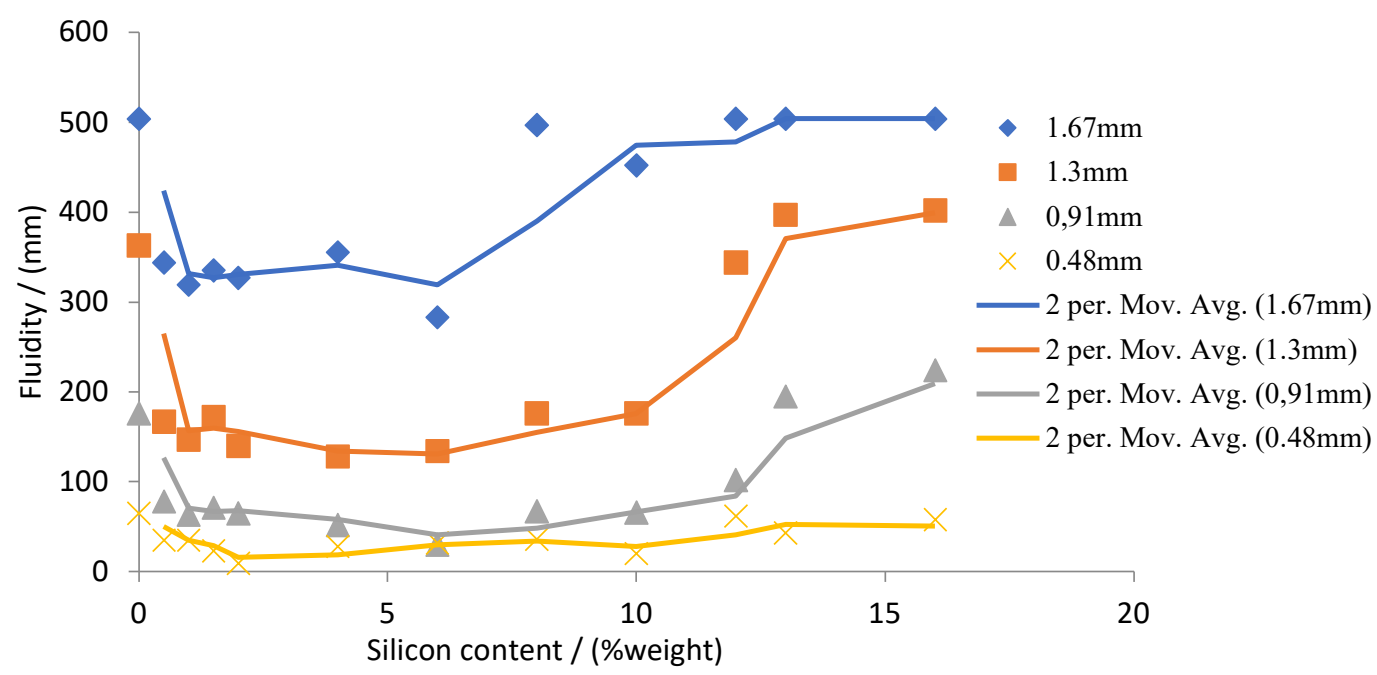

Figure 3: Fluidity of alloys treated with Ti-B-Al as a function of silicon content and test channel modulus.

Figure 4 shows the percentage increase in the fluidity of the alloys treated with Ti-B-Al over those that were not treated as a function of silicon content and channel modulus. The general effect of Ti-B-Al on the fluidity of the alloys was to cause a change between $-40 \%$ and $+20 \%$ in the fluidity. In solid solution alloys, the effect of Ti-B$\mathrm{Al}$ was a general change of $\pm 20 \%$. In the hypo-eutectic alloys addition of Ti-B-Al caused general decrease between $20 \%$ and $40 \%$ in the fluidity of the alloys.

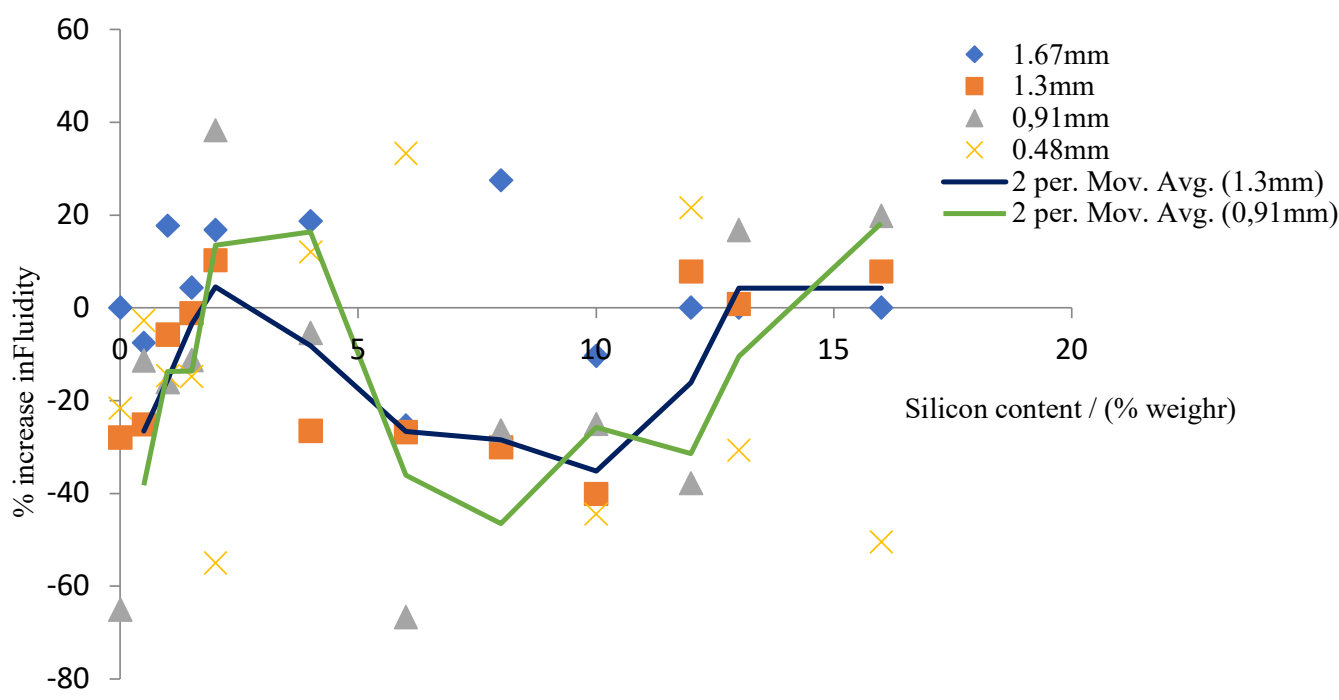

Figure 4: Percentage increase in fluidity (due to addition of Ti-B-Al) as a function of silicon content and channel modulus

The largest effect of Ti-B-Al addition was on the fluidity of pure aluminum which was a decrease of $65 \%$ (minimum) in the $1.9 \mathrm{~mm}$ modulus channel. This may be attributed to a change in the mode of solidification of the aluminum from a planar solidification growth front to the growth of equiaxed dendrites as indicated by Figure 5 . The shape of the shrinkage pores in Figure 5, however, is intermediate between the needle like shape observed in the pure metal and round shrinkage pores observed in the alloys (Adefuye, 2006). This implies that the solidification front near the tip is not as unstable as in the alloys and still shows some element of progressive growth from the walls to the center of the channel hence, the comparatively high fluidity of the pure aluminum treated with Ti-B-Al. 


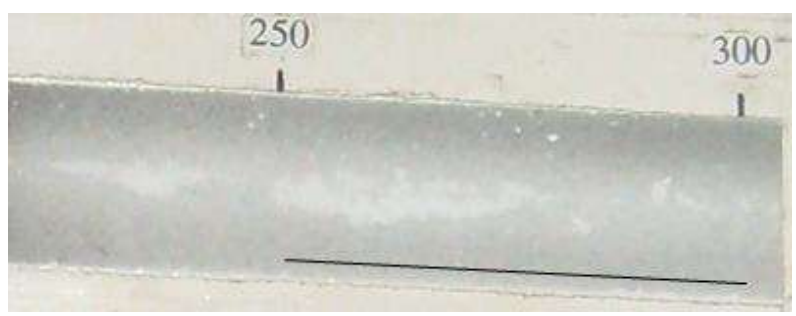

Figure 5: X-ray radiograph showing the shrinkage porosity along the length of the fluidity test strip of pure aluminum treated with Ti-B-Al. (The figures are the distance of the points from the channel inlet in millimeters.

The dark line is a scale measuring $10 \mathrm{~mm}$ ).

The general decrease in fluidity of the hypo-eutectic alloys was caused by the fact that the Ti-B-Al was very efficient in nucleating primary aluminum. In fact, the primary aluminum observed in the hypo-eutectics was of the rosette morphology. The nuclei formed in the treated alloys were more than those in the untreated alloys and they grew to attain the critical volume before those in the untreated alloys.

\section{Conclusion}

A suitable base line fluidity data for Al-Si casting alloys with adequate representation of all types of alloys on the Al-Si system was generated. The addition of $0.117 \%$ by weight of titanium and $0.023 \%$ by weight of boron to liquid pure aluminum in form of Ti-B-Al reduced the fluidity of pure aluminum in the $0.91 \mathrm{~mm}$ modulus channel by at least $65 \%$. The reduction was achieved by causing a change in the flow arrest mechanism from arrest by growth of planar solidification front to arrest by presence of critical volume of equiaxed dendrites.

The fluidity of each hypo-eutectic Al-Si alloys was significantly decreased by the addition of Ti-B-Al. This occurred because Ti-B-Al addition increased the number of nuclei, hence reducing the time needed to attain the critical amount of volume of dendrites required to arrest the flow. This consequently decreased the fluidity. In the hyper-eutectic alloys the addition Ti-B-Al increased the fluidity of the alloys by between $8 \%$ and $18 \%$.

\section{Acknowledgement}

This author wishes to thank the Association of Commonwealth Universities (ACU) and Professor John Campbell and the casting group Centre for the Development of Materials for high technical application and Cadbury Bourneville Birmingham U.K. for sponsoring this work. Thank you.

\section{References}

Adefuye, O. A. (2006). The effect of sodium modification of the eutectic structure on the fluidity of Al-Si alloys. In: Proceedings Materials Science and Technology Conference, October 15-19, 2006, Cincinnati, Ohio, USA.

Adefuye, O. A. (2014). Casting fluidity of commercially pure Al-Si casting alloys. Transactional Journal of Science and Technology, 4(1):16-30.

Birol, Y. (2012). Performance of AlTi5B1, AlTi3B3 and AlB3 master alloys in refining grain structure of aluminium foundry alloys. Material Science and Technology, 28(4):481-486.

Birol, Y. (2013). Efficiency of binary and ternary alloys from Al-Ti-B system in grain refining aluminium alloys. International Journal of Cast Metals Research, 26(5):283-288.

Bolzoni, L. and Babu, N. H. (2019). Efficacy of borides in grain refining Al-Si alloys. Metallurgical and Materials Transactions A, 50(2): 746-756.

Bolzoni, L., Nowak, M. and Hari Babu, N. (2013). Influence of a novel master alloy addition on the grain refinement of Al-Si cast alloys. Materials Science Forum, 765:311-315.

Campbell, J. (1995). Review of fluidity concepts in casting. Cast Metals, 7(4):227-237.

Campbell, J. (2003). Castings. Elsevier.

Di Sabatino, M. (2005). Fluidity of aluminium foundry alloys. PhD Thesis, Norwegian University of Science and Technology (NTNU), Trondheim.

Di Sabatino, M. and Arnberg, L. (2004). A review on the fluidity of Al based alloys. Metallurgical Science and Technology, 22(1):9-15.

Easton, M. A., Qian, M., Prasad, A. and StJohn, D. H. (2016). Recent advances in grain refinement of light metals and alloys. Current Opinion in Solid state and Materials Science, 20(1):13-24.

Kumar, V., Mehdi, H. and Kumar, A. (2015). Effect of silicon content on the mechanical properties of aluminum alloy. International Research Journal of Engineering and Technology, 2(4):1326-1330.

Niu, G., Mao, J. and Wang, J. (2019). Effect of Ce addition on fluidity of casting aluminium alloy A356. Metallurgical and Materials Transactions A, 50(12):5935-5944. 
Piwonka, T. S. (1998). Solidification of metal and alloys. In: Metals Handbook Desk Edition, Second Edition, (Ed: Davis, J. R.), ASM International.

Quested, T. E. (2004). Understanding mechanisms of grain refinement of aluminium alloys by inoculation. Material Science and Technology, 20(11): 1357-1369.

Ravi, K. R., Pillai, R. M., Amaranathan, K. R., Pai. B. C. and Chakraborty, M. (2008). Fluidity of aluminium alloys and composites: a review. Journal of Alloys and Compounds, 456(1-2):201-210.

Spittle, J. A. (2006). Grain refinement in shape casting of aluminium alloys. International Journal of Cast Metals Research, 19(4):210-222.

Sunitha, K. and Gurusami, K. (2020). Study of Al-Si alloys grain refinement by inoculation. Materials Today: Proceedings (in press). 